\title{
PENGARUH PERBANDINGAN BUBUK KULIT ARI BIJI KAKAO : EKSTRAK KULIT BUAH JERUK NIPIS DAN WAKTU PENGADUKAN TERHADAP KARAKTERISTIK BODI KRIM

\author{
The Efect of the Comparison of the Bark Powder of Cocoa Beans: Extract of Lime Peel and
} the Stirring Time on the Characteristics of Body Cream
}

I Gusti Ayu Agung Putri Utami, G. P. Ganda Putra*, Luh Putu Wrasiati,

PS Teknologi Industri Pertanian, Fakultas Teknologi Pertanian, Universitas Udayana, Kampus Bukit Jimbaran, Badung, Kode pos : 80361; Telp/Fax : (0361) 701801.

Diterima 30 Oktober 2018 / Disetujui 03 Februari 2019

\begin{abstract}
Cream is a cosmetics in the form of a half-solid emulsion. This study aims to determine the effect of the comparison of the bark powder of the cocoa beans : extract of lime peel and the stirring time on the characteristics of body cream, determine the comparison of the bark powder of the cocoa beans : extract of lime peel and the stirring time that is best to produce body cream. This study uses factorial completely randomized design with 2 factors. The first factor is the comparison of the bark powder of the cocoa beans : extract of lime peel. The second factor is the stirring time of the body cream. The variables observed were material moisture content, $\mathrm{pH}$, viscosity, dispersion, separation ratio, antioxidant capacity and color intensity. The results showed that the comparative treatment of the addition of the bark powder of cocoa beans and lime peel extract had a very significant effect on $p H$, dispersion, antioxidant capacity, brightness level $\left(L^{*}\right)$, redness level $\left(a^{*}\right)$, and yellowish level $\left(b^{*}\right)$ cream. The stirring time treatment has a significant effect on the brightness level $(L *)$ of the cream. Comparative treatment of adding the bark powder of cocoa beans and extracts of lime peel, stirring time and interaction between the two treatments has a very significant effect on the viscosity of the cream. The comparison of the addition of the bark powder of cocoa beans : lime peel extract are 7.14: 7.14 grams and 15 minutes of stirring time was the best treatment, which can produce body cream with characteristic of $\mathrm{pH} 6,35$, dispersion level $6,10 \mathrm{~cm}$, viscosity $28.100 \mathrm{cp}$, separation ratio $=1$, antioxidant capacity 125, $33 \mathrm{mg}$ GAEAC/L, brightness level $\left(L^{*}\right) 43,78$, redness level ( $\left.a^{*}\right)$ 6,73 and yellowish level $\left(b^{*}\right) 10,56$.
\end{abstract}

Keywords : body cream, addition of ingredients, and stirring time.

\section{ABSTRAK}

Krim merupakan kosmetik berbentuk setengah padat yang berupa emulsi. Penelitian ini bertujuan untuk mengetahui pengaruh perbandingan bubuk kulit ari biji kakao : ekstrak kulit buah jeruk nipis dan waktu pengadukan terhadap karakteristik bodi krim, serta untuk menentukan perbandingan bubuk kulit ari biji kakao : ekstrak kulit buah jeruk nipis dan waktu pengadukan terbaik untuk pembuatan bodi krim. Penelitian ini menggunakan Rancangan Acak Lengkap faktorial, dengan 2 faktor sebagai perlakuan. Faktor pertama yaitu perbandingan bubuk kulit ari biji kakao: ekstrak kulit buah jeruk nipis. Faktor kedua yaitu variasi waktu pengadukan bodi krim. Variabel yang diamati pada pembuatan krim adalah

\footnotetext{
*Korespondensi Penulis:

Email : gandaputra@unud.ac.id
} 
kadar air bahan, $\mathrm{pH}$, viskositas, daya sebar, rasio pemisahan, kapasitas antioksidan, intensitas warna. Hasil penelitian menunjukkan perbandingan bubuk kulit ari biji kakao dan ekstrak kulit buah jeruk nipis berpengaruh sangat nyata terhadap $\mathrm{pH}$, daya sebar, kapasitas antioksidan, tingkat kecerahan $\left(\mathrm{L}^{*}\right)$, tingkat kemerahan $\left(a^{*}\right)$, dan tingkat kekuningan $\left(b^{*}\right)$ krim. Perlakuan waktu pengadukan berpengaruh nyata terhadap tingkat kecerahan $\left(\mathrm{L}^{*}\right) \mathrm{krim}$. Perlakuan perbandingan penambahan bahan bubuk kulit ari biji kakao dan ekstrak kulit buah jeruk nipis, waktu pengadukan serta interaksi antara kedua perlakuan sangat berpengaruh terhadap viskositas krim. Perbandingan bubuk kulit ari biji kakao dan ekstrak kulit buah jeruk nipis 7,14: 7,14 gram serta waktu pengadukan 15 menit merupakan perlakuan terbaik yang dapat menghasilkan produk bodi krim, dengan karakteristik nilai $\mathrm{pH} 6,35$, daya sebar $6,10 \mathrm{~cm}$, viskositas $28.100 \mathrm{cp}$, rasio pemisahan $=1$, kapasitas antioksidan $125,33 \mathrm{mg}$ GAEAC/L, tingkat kecerahan $\left(\mathrm{L}^{*}\right)$ 43,78, tingkat kemerahan $\left(a^{*}\right)$ 6,73 dan tingkat kekuningan ( $\left.b^{*}\right)$ 10,56.

Kata kunci : bodi krim, penambahan bahan, waktu pengadukan

\section{PENDAHULUAN}

Kakao merupakan komoditas andalan perkebunan Indonesia. Bagian dari buah kakao yang biasa dikonsumsi adalah bagian bijinya. Biji kakao terdiri dari dua bagian, yaitu kulit ari dan keping biji. Kulit ari biji kakao berpeluang untuk dimanfaatkan sebagai sumber antioksidan karena mengandung senyawa polifenol dengan total fenolik sebesar 5,78\% (Lecumberry et al., 2007). Fungsi polifenol yaitu sebagai penangkap radikal bebas dari rusaknya ionion logam. Polifenol yang terdapat pada kulit ari biji kakao yaitu prosianidin, epikatekin, phydroksibenzoic acid, antosianin, proantosianidin dan clovamid (Arlorio et al., 2005). Polifenol yang terkandung dalam kulit ari biji kakao dapat memperlambat penuaan dini dan melancarkan peredaran darah. Antioksidan alami lainnya juga dapat dijumpai pada buah jeruk. Diantara berbagai jenis buah jeruk yang tersedia, jeruk nipis merupakan jeruk yang paling banyak mengandung flavonoid. Selain itu buah jeruk nipis juga mengandung senyawa berupa saponin dan minyak atsiri. Pada bagian kulitnya, terkandung flavonoid seperti naringin, hesperidin, naringenin, hesperitin, rutin, nobiletindan tangeretin (Adindaputri et al. 2013).

Pada sediaan kosmetik, antioksidan berfungsi sebagai penangkal radikal bebas, serta berperan sebagai pengawet agar umur simpan produk menjadi lebih tahan lama. Sediaan kosmetik dari luar yang sering digunakan seharihari adalah krim. Krim merupakan bentuk kosmetik berbentuk setengah padat yang berupa emulsi. Krim mengandung tidak kurang dari $60 \%$ air karena dalam produksinya dimaksudkan untuk pemakaian bagian luar tubuh. Umumnya krim dibagi menjadi dua tipe emulsi, yaitu tipe minyak dalam air (M/A) dan tipe air dalam minyak (A/M). Emulsi jenis minyak dalam air lebih disukai karena sifatnya yang mudah dibersihkan dari pada kebanyakan salep (Ansel,2005).

Penelitian Umaroh (2015) tentang pembuatan lulur bekatul dengan menggunakan bahan tambahan berupa ekstrak kulit buah kakao dan ekstrak kulit buah jeruk nipis. Hasil uji organoleptik terbaik lulur bekatul diperoleh perbandingan $2: 1,(20 \%$ ekstrak kulit buah kakao dan $10 \%$ ekstrak kulit buah jeruk nipis).

Penelitian Dewi et al. (2014) menyatakan pembuatan krim yang mengandung ekstrak kacang kedelai menggunakan perlakuan kecepatan pengadukan sebesar $3000 \mathrm{rpm}$ dengan menggunakan alat homogenizer selama 10 menit. Kecepatan pengadukan sebesar 3000 rpm dengan waktu 10 menit dapat diartikan bahwa krim tersebut diaduk sebanyak 30.000 kali pengadukan. Kecepatan tersebut dianggap sebagai kecepatan terbaik pada penelitian sebelumnya.

Penelitian ini memodifikasi formulasi krim dengan menghilangkan bahan berupa bekatul dan menggunakan perbandingan 
bubuk kulit ari biji kakao dan ekstrak kulit buah jeruk nipis yaitu $1: 1,2: 1$ dan $3: 1$, Selain itu, kecepatan pengadukan juga dikonversi ke dalam bentuk waktu, dengan 3 variasi yaitu 15 menit, 30 menit, dan 45 menit pada kecepatan $1000 \mathrm{rpm}$. Penelitian ini bertujuan untuk mengetahui pengaruh perbandingan bubuk kulit ari biji kakao : ekstrak kulit buah jeruk nipis dan waktu pengadukan terhadap karakteristik bodi krim, serta untuk menentukan perbandingan bubuk kulit ari biji kakao : ekstrak kulit buah jeruk nipis dan waktu pengadukan terbaik untuk pembuatan bodi krim.

\section{METODE PENELITIAN}

\section{Bahan dan Alat}

Bahan-bahan yang digunakan dalam pembuatan krim antara lain kulit ari biji kakao sangrai yang diperoleh dari UD. Sari Harta, kulit buah jeruk nipis yang diperoleh dari rumah makan di sekitaran Mengwi, tween 80 (Olympus), span 80 (Olympus) diperoleh dari Djlahware Medical and Laboratory Supplies, akuades, propilen glikol, asam stearat, gliserin, VCO (Viconut), dan setil alkohol diperoleh dari Toko Saba Kimia, air untuk pembuatan hidrosol diperoleh dari laboratorium Analisis Pangan FTP Unud. Bahan untuk analisis diperoleh dari laboratorium Analisis Pangan FTP Unud adalah asam galat (Merck), DPPH (Sigma Aldrich), methanol (Emsure).

Peralatan yang digunakan dalam penelitian ini adalah timbangan analitik (Shimadzu), blender (Phillips HR 2115), sendok plastik, kuas, spatula, kertas saring biasa, wadah plastik, aluminium foil, peralatan gelas (Pyrex), corong, ayakan 80 mesh, viskometer (Brokfield), magnetic stirrer (Dlab MS-H-S), waterbath shaker (SWBR 17 Shaking Water Bath), vortex (Barntard Thermolyne Maxi Mix II), pHmeter Beckman, centrifuge (Yenaco), colour reader, spektrofotometer (Genesys $105 \mathrm{UV}$ -
VIS).

\section{Pelaksanaan Penelitian}

Kulit ari biji kakao yang telah kering dihaluskan dengan menggunakan blender, kemudian diseragamkan ukurannya dengan menggunakan ayakan berukuran 80 mesh, Bubuk yang diperoleh kemudian diuji kadar airnya. Setelah itu bubuk siap digunakan sebagai bahan krim.

Setelah diperoleh bubuk kulit ari biji kakao, kemudian dilanjutkan dengan pembuatan hidrosol kulit buah jeruk nipis berdasarkan penelitian Nindyasari (2012) dengan modifikasi. Pembuatan hidrosol diawali dengan memotong kulit buah jeruk nipis menjadi ukuran 1-2 mm, kemudian dikering-anginkan dengan menutupnya dengan kain hitam. Bahan yang telah kering ditimbang sebanyak 150 gram dan dimasukan ke dalam toples yang dituangi dengan air sebanyak $1500 \mathrm{ml}$, ditutup dan dibiarkan selama 24 jam terlindung dari cahaya. Setelah 24 jam, larutan disaring dengan menggunakan kertas saring. Larutan hasil penyaringan ditampung dan hidrosol siap untuk digunakan sebagai bahan krim .

Pembuatan basis sediaan krim dilakukan dengan mencampurkan bahan berupa oil base dan water base. Bahan yang dicampur terdiri dari bahan water base (fase air) dan bahan oil base (fase minyak). Bahan oil base terdiri atas VCO 5 gram, setil alkohol 1,43 gram dan span 80 sebanyak 5,34 gram. Water base terdiri atas 7,1 gram propilen glikol, 14,28 gram gliserin, 9,88 gram tween 80 dan akuades 100 gram. Sebelum mencampur kedua fase, bahan tambahan krim berupa bubuk kulit ari kakao (kabk) dan ekstrak kulit buah jeruk nipis (kbjn) ditambahkan ke dalam water base yaitu dengan perbandingan $1: 1,2: 1$ dan $3: 1$, kemudian fase air dicampur dan dipanaskan pada suhu $70^{\circ} \mathrm{C}$. Fase minyak juga dipanaskan hingga suhu mencapai $70^{\circ} \mathrm{C}$, hal ini berfungsi untuk melarutkan semua bahan 
yang telah dicampurkan. Setelah tersedia water base maupun oil base, bahan oil base dituangkan sedikit demi sedikit ke dalam bahan water base, kemudian diaduk dengan menggunakan magnetic stirer. Pada proses pengadukan dengan menggunakan magnetic stirer, diberikan perlakuan waktu pengadukan yang berbeda-beda yaitu 15 menit, 30 menit dan 45 menit, dengan kecepatan pengadukan $1000 \mathrm{rpm}$. Sediaan krim yang telah selesai diaduk, kemudian ditempatkan pada wadah plastik yang tertutup rapat dan diberi label unuk untuk dianalisis. Berikut formulasi krim yang dapat dilihat pada Tabel 1.

Tabel 1. Formulasi krim bubuk kulit ari biji kakao : ekstrak kulit buah jeruk nipis

\begin{tabular}{llll}
\hline & \multicolumn{3}{c}{ Jumlah (gram) } \\
\cline { 2 - 4 } & $\mathrm{P} 1$ & $\mathrm{P} 2$ & $\mathrm{P} 3$ \\
\hline Propilen glikol & 7,10 & 7,10 & 7,10 \\
Setil alkohol & 1,43 & 1,43 & 1,43 \\
Gliserin & 14,28 & 14,28 & 14,28 \\
Span 80 & 5,34 & 5,34 & 5,34 \\
Tween 80 & 9,88 & 9,88 & 9,88 \\
VCO & 5 & 5 & 5 \\
Bubuk kabk : & $7,14: 7,14$ & $9,43: 4,86$ & $10,71: 3,57$ \\
ekstrak kbjn & $(1: 1)$ & $(2: 1)$ & $(3: 1)$ \\
Penambahan & 100 & 100 & 100 \\
akuades hingga & & & \\
\hline
\end{tabular}

Sumber : Kusumowardani (2010) dengan modifikasi

\section{Variabel yang Diamati}

Variabel yang diamati pada pembuatan krim adalah kadar air bahan (AOAC, 2005), pH (Iswindari, 2014), viskositas (Badan Standarisasi Nasional, 1996), daya sebar (Voight, 1994), rasio pemisahan (Smaoui et al. 2012), kapasitas antioksidan (Yunilawati, 2011), intensitas warna (Weaver , 1996).

\section{HASIL DAN PEMBAHASAN}

\section{Kadar Air Bahan Baku Krim}

Hasil pengujian kadar air bubuk kulit ari biji kakao diperoleh nilai rata-rata yaitu sebesar 4,9 $\pm 0,19 \%$. Nilai maksimal kadar air bubuk kulit ari biji kakao yang baik yaitu sebesar 7\%. Dari hasil yang diperoleh kadar air bubuk kulit ari biji kakao yaitu 4,9\%, nilai tersebut menunjukan bahwa kadar air yang terkandung pada bubuk kulit ari biji kakao rendah sehingga dapat mengurangi resiko kerusakan bahan. Kadar air bahan baku produk yang rendah akan membuat bahan menjadi lebih awet dan tidak mudah berjamur pada saat penyimpanan bahan baku.

\section{Derajat Keasaman (pH)}

Hasil analisis keragaman menunjukkan bahwa perbandingan bubuk kulit ari biji kakao dan ektrak kulit buah jeruk nipis berpengaruh sangat nyata $(\mathrm{P}<0,01)$, tetapi perlakuan waktu pengadukan dan interaksi antar perlakuan berpengaruh tidak nyata $(\mathrm{P}>0,05)$ terhadap $\mathrm{pH}$ krim. Nilai rata-rata $\mathrm{pH}$ krim bubuk kulit ari biji kakao dan ekstrak kulit buah jeruk nipis dapat dilihat pada Tabel 2.

Tabel 2 menunjukan bahwa nilai ratarata $\mathrm{pH}$ pada tiap sampel dengan perbandingan bubuk kulit ari biji kakao : ekstrak kulit buah jeruk nipis $1: 1,2: 1$ dan 3 : 1 mengalami penuruan. Semakin banyak penambahan bubuk kulit ari biji kakao maka nilai $\mathrm{pH}$ akan semakin menurun atau $\mathrm{pH}$ krim menjadi semakin asam. Kedua bahan tersebut mengandung senyawa asam sehingga 
menyebabkan nilai rata-rata $\mathrm{pH}$ dari tiap produk mengalami penurunan. Pada tiap produk penambahan bubuk kulit ari biji kakao meningkat, sedangkan penambahan ekstrak kulit buah jeruk nipis tetap. Meskipun demikian, nilai rata-rata $\mathrm{pH}$ dari tiap produk akan menurun, karena senyawa asam pada bubuk kulit ari biji kakao menyumbangkan lebih banyak senyawa asam dibandingkan dengan ekstrak kulit buah jeruk nipis berdasarkan perbandingan bahan yang telah ditentukan karena jumlah penambahan bubuk kulit ari biji kakao meningkat. Pada bubuk kulit ari biji kakao terdapat asam organik seperti asam asetat $0,10 \%$, asam sitrat $0,70 \%$ dan asam oksalat 0,30\% (Minifie, 1984). Berdasarkan hasil yang didapatkan, nilai ratarata $\mathrm{pH}$ krim masih berada pada kisaran nilai standar SNI 16-4399-1996 yaitu 4,5 - 6,5. Krim yang baik adalah krim yang memiliki nilai $\mathrm{pH}$ yang sama dengan $\mathrm{pH}$ normal kulit, sehingga aman untuk digunakan. Nilai $\mathrm{pH}$ pada suatu kosmetik merupakan hal yang sangat penting untuk diketahui, agar dalam penggunaannya dikulit tidak menimbulkan iritasi.

Tabel 2. Nilai rata-rata pH krim bubuk kulit ari biji kakao dan ekstrak kulit buah jeruk nipis

\begin{tabular}{|c|c|c|c|c|}
\hline \multirow{2}{*}{$\begin{array}{l}\text { Perbandingan Bubuk } \\
\text { kulit ari biji kakao : } \\
\text { Ekstrak kulit buah jeruk } \\
\text { nipis (gram) }\end{array}$} & \multicolumn{3}{|c|}{ Waktu Pengadukan (Menit) } & \multirow[t]{2}{*}{ Rata-rata } \\
\hline & 15 & 30 & 45 & \\
\hline $7,14: 7,14(1: 1)$ & 6,35 & 6,30 & 6,33 & $6,33 \pm 0,03 a$ \\
\hline $9,43: 4,86(2: 1)$ & 6,18 & 6,18 & 6,18 & $6,18 \pm 0,00 b$ \\
\hline $10,71: 3,57(3: 1)$ & 6,15 & 6,15 & 6,15 & $6,15 \pm 0,00 \mathrm{~b}$ \\
\hline
\end{tabular}

$\begin{array}{llll}\text { Rata-rata } & 6,23 \pm 0,11 \text { a } & 6,21 \pm 0,08 \text { a } & 6,22 \pm 0,10 \text { a }\end{array}$

Keterangan : Huruf berbeda di belakang nilai rata-rata pada baris dan kolom yang sama menunjukan perbedaan yang sangat nyata $(\mathrm{P}<0,01)$.

\section{Daya Sebar}

Hasil analisis keragaman menunjukkan bahwa perlakuan perbandingan bubuk kulit ari biji kakao dan ektrak kulit buah jeruk nipis berpengaruh sangat nyata $(\mathrm{P}<0,01)$, tetapi perlakuan waktu pengadukan dan interaksi antar perlakuan berpengaruh tidak nyata $(\mathrm{P}>0,05)$ terhadap daya sebar krim. Nilai ratarata daya sebar krim bubuk kulit ari biji kakao dan ekstrak kulit buah jeruk nipis dapat dilihat pada Tabel 3 .

Tabel 3. Nilai rata-rata daya sebar $(\mathrm{cm})$ krim bubuk kulit ari biji kakao dan ekstrak kulit buah jeruk nipis

\begin{tabular}{|c|c|c|c|c|}
\hline \multirow{2}{*}{$\begin{array}{l}\text { Perbandingan Bubuk } \\
\text { kulit ari biji kakao : } \\
\text { Ekstrak kulit buah } \\
\text { jeruk nipis (gram) }\end{array}$} & \multicolumn{3}{|c|}{ Waktu Pengadukan (menit) } & \multirow[t]{2}{*}{ Rata-rata } \\
\hline & 15 & 30 & 45 & \\
\hline $7,14: 7,14(1: 1)$ & 6,10 & 5,53 & 5,28 & $5,64 \pm 0,42 a$ \\
\hline $9,43: 4,86(2: 1)$ & 4,78 & 4,70 & 4,55 & $4,68 \pm 0,12 b$ \\
\hline $10,71: 3,57(3: 1)$ & 4,58 & 4,43 & 4,43 & $4,48 \pm 0,09 b$ \\
\hline Rata-rata & $5,15 \pm 0,83 a$ & $4,89 \pm 0,57 a$ & $4,75 \pm 0,46 a$ & \\
\hline
\end{tabular}

Keterangan : Huruf berbeda di belakang nilai rata-rata pada kolom yang sama menunjukan perbedaan yang sangat nyata $(\mathrm{P}<0,01)$.

Tabel 3 menunjukan nilai rata-rata diameter daya sebar krim yang paling tinggi diperoleh dari perlakuan penambahan bahan bubuk kulit ari biji kakao : ekstrak kulit buah 
jeruk nipis $1: 1$ yaitu $5,64 \mathrm{~cm}$. Nilai rata-rata diameter daya sebar krim terendah diperoleh dari perlakuan penambahan bahan bubuk kulit ari biji kakao : ekstrak kulit buah jeruk nipis $3: 1$ yaitu $4,48 \mathrm{~cm}$.

Daya sebar krim yang menurun disebabkan oleh meningkatnya jumlah bubuk kulit ari biji kakao yang ditambahkan, karena bubuk kulit ari biji kakao memiliki sifat menyerap air. Semakin banyak bubuk kulit ari biji kakao yang ditambahkan, maka daya sebar krim yang dihasilkan akan semakin rendah karena kandungan airnya yang lebih sedikit. Penambahan bubuk kulit ari biji kakao yang sedikit akan menyebabkan bahan akan stabil dan tidak susah untuk tercampur pada sediaan. Selain itu, daya sebar krim juga berhubungan erat dengan kekentalan krim. Semakin kental sediaan maka diameter penyebaran akan semakin kecil. Standar daya sebar yang baik untuk sediaan topikal adalah 5-7 cm (Rachmalia et al., 2016).

\section{Viskositas}

Tabel 4. Nilai rata-rata viskositas (cp) krim bubuk kulit ari biji kakao dan ekstrak kulit buah jeruk nipis

\begin{tabular}{lccc}
\hline \multirow{2}{*}{$\begin{array}{l}\text { Perbandingan Bubuk kulit } \\
\text { ari biji kakao : Ekstrak }\end{array}$} & \multicolumn{3}{c}{ Waktu Pengadukan (Menit) } \\
$\begin{array}{l}\text { kulit buah jeruk nipis } \\
\text { (gram) }\end{array}$ & $\mathbf{1 5}$ & $\mathbf{3 0}$ & $\mathbf{4 5}$ \\
\hline $7,14: 7,14(1: 1)$ & $28.100 \pm 141 \mathrm{i}$ & $30.900 \pm 141 \mathrm{~h}$ & $33.200 \pm 0,00 \mathrm{~g}$ \\
$9,43: 4,86(2: 1)$ & $34.900 \pm 141 \mathrm{f}$ & $35.900 \pm 141 \mathrm{e}$ & $38.100 \pm 141 \mathrm{~d}$ \\
$10,71: 3,57(3: 1)$ & $40.200 \pm 283 \mathrm{c}$ & $42.900 \pm 141 \mathrm{~b}$ & $44.800 \pm 0,00 \mathrm{a}$ \\
\hline $\begin{array}{l}\text { Keterangan : Huruf berbeda di belakang nilai rata-rata menunjukan perbedaan yang sangat nyata }(\mathrm{P}<0,01) . \text { Data } \\
\text { merupakan rata-rata dari 2 ulangan perlakuan. }\end{array}$
\end{tabular}

Semakin meningkatnya jumlah bubuk kulit ari biji kakao yang ditambahkan maka akan menyebabkan kandungan air bahan rendah karena sifat kulit ari biji kakao yang menyerap air, serta penambahan bahan bubuk kulit ari biji kakao lebih banyak jumlahnya dibandingkan dengan ekstrak kulit buah jeruk nipis yang mengandung air. Semakin meningkatnya waktu pengadukan, maka nilai viskositas krim akan semakin meningkat
Hasil analisis keragaman menunjukkan bahwa perbandingan bubuk kulit ari biji kakao dan ektrak kulit buah jeruk nipis, perlakuan waktu pengadukan dan interaksi antar perlakuan berpengaruh sangat nyata $(\mathrm{P}<0,01)$ terhadap viskositas krim. Nilai ratarata viskositas krim bubuk kulit ari biji kakao dan ekstrak kulit buah jeruk nipis dapat dilihat pada Tabel 4. Tabel 4 menunjukan adanya peningkatan nilai viskositas berdasarkan perbedaan perbandingan penambahan bahan bubuk kulit ari biji kakao : ekstrak kulit buah jeruk nipis dan waktu pengadukannya. Nilai viskositas terendah diperoleh dari sampel dengan perbandingan penambahan bahan bubuk kulit ari biji kakao : ekstrak kulit buah jeruk nipis 1 : 1 dengan waktu pengadukan 15 menit yaitu $18.100 \mathrm{cp}$, sementara nilai viskositas tertinggi $44.800 \mathrm{cp}$ diperoleh dari sampel dengan perbandingan penambahan bahan jeruk nipis $3: 1$ dengan waktu pengadukan 45 menit. bubuk kulit ari biji kakao : ekstrak kulit buah 
emulgator belum melapisi globul secara sempurna sedangkan jika waktu pengadukan terlalu lama dapat menyebabkan terjadinya tumbukan antar globul minyak yang dapat menyebabkan koelesensi. Nilai viskositas yang baik memiliki nilai yang tinggi, semakin tinggi viskositas maka pergerakan partikel akan semakin sulit sehingga bahan akan menjadi stabil (Schmitt,1996). Kandungan air yang rendah pada bahan dapat menyebabkan konsentrasi emulsifier mengalami peningkatan, sehingga viskositas emulsi semakin meningkat.

\section{Rasio Pemisahan}

Uji rasio pemisahan krim dilakukan dengan menggunakan metode setrifugasi. Pengujian dilakukan dengan pengamatan terhadap krim, apakah terdapat pemisahan / perubahan antara tinggi fase krim dengan tinggi emulsi mula-mula dengan waktu pengamatan selama \pm 2 minggu. Emulsi dikatakan stabil jika nilai rasio pemisahan = 1 yang artinya bahwa emulsi tidak pecah atau memisah.

Berdasarkan hasil penelitian yang dilakukan, krim yang telah didiamkan selama \pm 2 minggu tidak mengalami pemisahan. Tinggi emulsi krim tidak berubah dari minggu pertama hingga minggu ke-2, sehingga dapat dikatakan krim memiliki nilai rasio pemisahan $=1$.

Zat pengemulsi atau emulgator berperan penting untuk menciptakan krim yang stabil. Ketidakstabilan fisik suatu emulsi atau suspensi dapat dipengaruhi oleh faktor-faktor yang mempengaruhi kestabilan kimia dari bahan pengemulsi (emulgator), suspending agent, antioksidan, pengawet dan bahan aktif. Kombinasi agen pengemulsi digunakan untuk meningkatkan sifat fisik dan stabilitas fisik suatu krim (Elfiyani et al. 2013), kombinasi agen pengemulsi yang digunakan pada pembuatan krim tersebut adalah asam stearat, span 80 dan tween 80 .

\section{Kapasitas Antioksidan}

Hasil analisis keragaman menunjukkan bahwa perbandingan bubuk kulit ari biji kakao dan ektrak kulit buah jeruk nipis berpengaruh sangat nyata $(\mathrm{P}<0,01)$, tetapi perlakuan waktu pengadukan dan interaksi antar perlakuan berpengaruh tidak nyata $(\mathrm{P}>0,05)$ terhadap kapasitas antioksidan krim. Nilai rata-rata kapasitas antiosidan krim krim bubuk kulit ari biji kakao dan ekstrak kulit buah jeruk nipis dapat dilihat pada Tabel 5.

Tabel 5 menunjukan bahwa nilai ratarata kapasitas antioksidan meningkat karena pengaruh perbandingan bubuk kulit ari biji kakao dan ekstrak kulit buah jeruk nipis yang ditambahkan pada tiap sampel meningkat. Kedua bahan yang ditambahkan sama-sama mengandung antioksidan yaitu polifenol dan flavonoid.

Tabel 5. Nilai rata-rata kapasitas antiosidan (mg GAEAC/L) krim bubuk kulit ari biji kakao dan ekstrak kulit buah jeruk nipis

\begin{tabular}{|c|c|c|c|c|}
\hline Perbandingan & \multicolumn{3}{|c|}{ Waktu Pengadukan (Menit) } & \multirow[t]{2}{*}{ Rata-rata } \\
\hline $\begin{array}{l}\text { kakao : } \\
\text { kulit bustrak } \\
\text { nipis (gram) }\end{array}$ & 15 & 30 & 45 & \\
\hline $7,14: 7,14(1: 1)$ & 125,33 & 133,54 & 132,09 & $130,30 \pm 4,38 \mathrm{c}$ \\
\hline $9,43: 4,86(2: 1)$ & 145,40 & 149,47 & 154,78 & $149,88 \pm 4,71 b$ \\
\hline $10,71: 3,57(3: 1)$ & 161,86 & 156,06 & 158,50 & $158,81 \pm 2,92 \mathrm{a}$ \\
\hline Rata-rata & $144,20 \pm 18,30 a$ & $146,36 \pm 11,57 \mathrm{a}$ & $148,46 \pm 14,30 \mathrm{a}$ & \\
\hline
\end{tabular}

Keterangan : Huruf berbeda di belakang nilai rata-rata pada kolom yang sama menunjukan perbedaan yang sangat nyata $(\mathrm{P}<0,01)$. 
Jumlah bubuk kulit ari biji kakao yang semakin meningkat menyebabkan kapasitas antioksidan pada tiap sampel juga meningkat meskipun penambahan ekstrak kulit buah jeruk nipisnya tetap. Nilai tersebut dipengaruhi oleh jumlah kandungan polifenol pada kulit ari biji kakao yang ditambahkan lebih tinggi dari pada kandungan flavonoid yang terkandung pada kulit jeruk nipis karena perbandingan formulasinya. Penelitian Sandrasari (2008) menyatakan bahwa suatu senyawa memiliki kapasitas antioksidan sangat kuat jika menghambat perkembangan radikal bebas lebih dari $80 \%$, sedangkan jika menghambat sebesar 50-80\% dan lemah jika memiliki penghambatan kurang dari $50 \%$.

\section{Intensitas Warna $\left(L^{*}, a^{*}, b^{*}\right)$}

Tingkat Kecerahan $\left(\mathbf{L}^{*}\right)$

Hasil analisis keragaman menunjukkan bahwa perlakuan perbandingan bubuk kulit ari biji kakao dan ekstrak kulit buah jeruk nipis berpengaruh sangat nyata $(\mathrm{P}<0,01)$, perlakuan waktu pengadukan berpengaruh nyata $(\mathrm{P}<0,05)$, tetapi interaksi antar perlakuan berpengaruh tidak nyata $(\mathrm{P}>0,05)$ terhadap tingkat kecerahan krim. Nilai ratarata tingkat kecerahan krim bubuk kulit ari biji kakao dan ekstrak kulit buah jeruk nipis dapat dilihat pada Tabel 6. Tabel 6 . menunjukan nilai rata - rata tingkat kecerahan krim semakin rendah karena adanya perbedaan perbandingan penambahan bahan dan waktu pengadukan. Nilai 0 menunjukan gelap atau hitam, sedangkan nilai 100 menunjukan sangat terang atau putih. Warna krim yang gelap dihasilkan oleh penambahan bubuk kulit ari biji kakao. Semakin banyak bubuk kulit ari biji kakao yang ditambahkan maka akan menghasilkan krim yang berwarna gelap, begitupun sebaliknya. Semakin lama waktu pengadukan krim maka tingkat kecerahan krim akan mengalami penurunan karena krim akan lebih lama terkena udara luar sehingga terjadi oksidasi. Hal tersebut sesuai dengan penelitian Sartini (2007) yang menyebutkan warna coklat yang terdapat pada kulit ari biji kakao dihasilkan karena terjadinya reaksi oksidasi pada kulit ari biji kakao jika terkena udara karena mengandung senyawa polifenol didalamnya.

Tabel 6. Nilai rata-rata tingkat kecerahan $\left(L^{*}\right)$ krim bubuk kulit ari biji kakao dan ekstrak kulit buah jeruk nipis

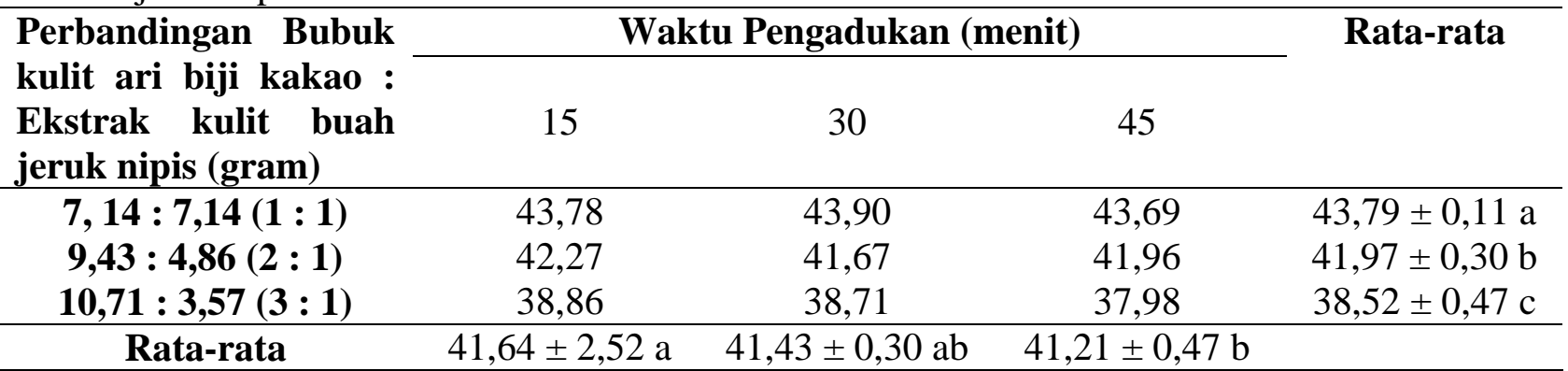

Keterangan : Huruf yang berbeda di belakang nilai rata-rata pada kolom dan baris yang sama menunjukan perbedaan yang sangat nyata $(\mathrm{P}<0,01)$.

\section{Tingkat Kemerahan (a*)}

Hasil analisis keragaman menunjukkan bahwa perlakuan penambahan bahan berupa perbandingan bubuk kulit ari biji kakao dan ektrak kulit buah jeruk nipis berpengaruh sangat nyata $(\mathrm{P}<0,01)$, perlakuan waktu pengadukan dan interaksi antar perlakuan berpengaruh tidak nyata $(\mathrm{P}>0,05)$ terhadap tingkat kemerahan krim. Nilai rata-rata tingkat kemerahan krim krim bubuk kulit ari biji kakao dan ekstrak kulit buah jeruk nipis dapat dilihat pada Tabel 7.

Tabel 7. menunjukkan bahwa nilai ratarata tingkat kemerahan tertinggi diperoleh 
dari perlakuan perbandingan penambahan bahan bubuk kulit ari biji kakao : ekstrak kulit buah jeruk nipis $1: 1$, sedangkan yang terendah diperoleh dari perbandingan penambahan bahan bubuk kulit ari biji kakao : ekstrak kulit buah jeruk nipis $2: 1$.

Nilai rata-rata tingkat kemerahan krim mengalami peningkatan disebabkan oleh penambahan bubuk kulit ari biji kakao yang mengandung tanin. Tanin menghasilkan warna merah kecoklatan pada suatu bahan. Semakin banyak bubuk kulit ari biji kakao yang ditambahkan maka semakin banyak kandungan senyawa tanin yang terkandung pada sediaan maka nilai tingkat kemerahannya akan semakin tinggi. Pada penelitian yang dilakukan, nilai rata-rata tingkat kemerahan yang diperoleh sangat rendah yaitu mendekati 0 , sehingga warna merah pada sampel tidak terlalu terlihat. Hal tersebut dapat disebabkan karena pigmen warna pada tanin rusak karena suhu yang tidak sesuai selama penyangraian biji kakao. Warna krim yang terlihat secara kasat mata yaitu berwarna kecoklatan. Tingkat kemerahan disimbolkan dengan nilai $+a^{*}$ (positif) dari 0 sampai +80 untuk warna merah.

Tabel 7. Nilai rata-rata tingkat kemerahan (a*) krim bubuk kulit ari biji kakao dan ekstrak kulit buah jeruk nipis

\begin{tabular}{lcccc}
\hline $\begin{array}{l}\text { Perbandingan } \\
\text { kulit ari biji kakao : }\end{array}$ & \multicolumn{3}{c}{ Waktu Pengadukan (menit) } & Rata-rata \\
$\begin{array}{l}\text { Ekstrak kulit buah } \\
\text { jeruk nipis (gram) }\end{array}$ & 15 & 30 & 45 & \\
\hline $\mathbf{7 , 1 4 : 7 , 1 4}(\mathbf{1}: \mathbf{1})$ & 6,73 & 6,76 & 6,76 & $6,75 \pm 0,02 \mathrm{c}$ \\
$\mathbf{9 , 4 3}: \mathbf{4 , 8 6}(\mathbf{2}: \mathbf{1})$ & 7,15 & 7,14 & 7,25 & $7,18 \pm 0,06 \mathrm{~b}$ \\
$\mathbf{1 0 , 7 1 : 3 , 5 7}(\mathbf{3}: \mathbf{1})$ & 7,59 & 7,70 & 7,52 & $7,60 \pm 0,09 \mathrm{a}$ \\
\hline
\end{tabular}

$\begin{array}{llll}\text { Rata-rata } & 7,16 \pm 0,43 \text { a } & 7,20 \pm 0,47 \text { a } & 7,18 \pm 0,39 \text { a }\end{array}$

Keterangan : Huruf berbeda di belakang nilai rata-rata pada kolom yang sama menunjukan perbedaan yang sangat nyata $(\mathrm{P}<0,01)$.

\section{Tingkat Kekuningan (b*)}

Hasil analisis keragaman menunjukkan bahwa perlakuan penambahan bahan berupa perbandingan bubuk kulit ari biji kakao dan ektrak kulit buah jeruk nipis berpengaruh sangat nyata $(\mathrm{P}<0,01)$, perlakuan waktu pengadukan dan interaksi antar perlakuan berpengaruh tidak nyata $(\mathrm{P}>0,05)$ terhadap tingkat kekuningan krim. Nilai rata-rata tingkat kekuningan krim krim bubuk kulit ari biji kakao dan ekstrak kulit buah jeruk nipis dapat dilihat pada Tabel 8 .

Tabel 8. Nilai rata-rata tingkat kekuningan $\left(b^{*}\right)$ krim bubuk kulit ari biji kakao dan ekstrak kulit buah jeruk nipis

\begin{tabular}{|c|c|c|c|c|}
\hline \multirow{2}{*}{$\begin{array}{l}\text { Perbandingan Bubuk } \\
\text { kulit ari biji kakao : } \\
\text { Ekstrak kulit buah } \\
\text { jeruk nipis (gram) }\end{array}$} & \multicolumn{3}{|c|}{ Waktu Pengadukan (menit) } & \multirow[t]{2}{*}{ Rata-rata } \\
\hline & 15 & 30 & 45 & \\
\hline $7,14: 7,14(1: 1)$ & 10,56 & 10,48 & 10,58 & $\begin{array}{c}10,54 \pm 0,05 \\
a\end{array}$ \\
\hline $\begin{array}{c}9,43: 4,86(2: 1) \\
10,71: 3,57(3: 1)\end{array}$ & $\begin{array}{l}9,75 \\
8,21\end{array}$ & $\begin{array}{l}9,80 \\
8,21\end{array}$ & $\begin{array}{l}9,82 \\
8,29\end{array}$ & $\begin{array}{l}9,79 \pm 0,04 b \\
8,24 \pm 0,05 c\end{array}$ \\
\hline Rata-rata & $9,51 \pm 1,19 \mathrm{a}$ & $9,50 \pm 1,17 \mathrm{a}$ & $9,56 \pm 1,17 \mathrm{a}$ & \\
\hline
\end{tabular}

Keterangan : Huruf berbeda di belakang nilai rata-rata pada kolom yang sama menunjukan perbedaan yang sangat nyata $(\mathrm{P}<0,01)$. 
Berdasarkan hasil penelitian, nilai ratarata tingkat kekuningan krim yang tertinggi diperoleh dari perlakuan perbandingan penambahan bahan bubuk kulit ari biji kakao : ekstrak kulit buah jeruk nipis $1: 1$, dengan nilai rata-rata yaitu sebesar 10,54. Nilai tingkat kekuningan terendah diperoleh oleh perlakuan perbandingan penambahan bahan bubuk kulit ari biji kakao : ekstrak kulit buah jeruk nipis $3: 1$ dengan nilai rata-rata 8,24.

Tabel 8 menunjukan nilai rata-rata tingkat kekuningan sampel mendekati angka 0 sehingga sesuai dengan penelitian Rizqi et al., (2014) yang menyebutkan derajat kekuningan menunjukan peningkatan nilai semakin mendekati angka 0 berati warna kuning yang terlihat akan semakin memudar, mendekati bening. Bahan yang berkontribusi memberikan zat warna kuning adalah ekstrak kulit buah jeruk nipis yang mengandung karotenoid, hal tersebut dapat dilihat dari hidrosol yang digunakan berwarna kuning muda. Produk krim yang telah di produksi tidak menunjukan adanya warna kuning secara kasat mata terlihat dari nilai $b^{*}$ yang diperoleh mendekati 0 . Hal tersebut terjadi karena penambahan ekstrak kulit buah jeruk nipis sedikit atau nilainya tetap, sehingga pigmen warna yang terdapat pada ekstrak kulit buah jeruk nipis terhalang oleh pigmen warna dari kulit ari biji kakao yang penambahannya terus meningkat.

\section{Hasil Uji Indeks Efektivitas Produk Krim Bubuk Kulit Ari Kakao dan Ekstrak Kulit Buah Jeruk Nipis}

Uji indeks efektivitas dilakukan untuk menentukan perlakuan terbaik untuk menghasilkan produk krim bubuk kulit ari biji kakao dan ektrak kulit buah jeruk nipis. Variabel yang diamati dalam uji indeks efektivitas ini yaitu, $\mathrm{pH}$, daya sebar, viskositas, rasio pemisahan, tingkat kecerahan ( $\left.\mathrm{L}^{*}\right)$, tingkat kemerahan (a*), tingkat kekuningan $\left(\mathrm{b}^{*}\right)$ dan kapasitas antioksidan. Hasil uji indeks efektivitas dapat dilihat pada Tabel 9.

Perlakuan terbaik ditunjukkan dengan nilai tertinggi dari penjumlahan nilai $\mathrm{Nh}$ pada tiap variabel. Tabel 9 menunjukkan bahwa perlakuan perbandingan bubuk kulit ari biji kakao : ekstrak kulit buah jeruk nipis 7,14 : 7,14 (1:1) dengan waktu pengadukan selama 15 menit mempunyai nilai tertinggi yaitu 0,46 . Hal tersebut menunjukkan bahwa perlakuan perbandingan penambahan bubuk kulit ari biji kakao : ekstrak kulit buah jeruk nipis $7,14: 7,14(1: 1)$ dengan waktu pengadukan selama 15 menit merupakan perlakuan terbaik yang dapat menghasilkan produk krim bubuk kulit ari biji kakao dan ektrak kulit buah jeruk nipis yang baik, sehingga dapat digunakan sebagai sediaan kosmetik yang dapat digunakan setiap hari pada kulit.

\section{KESIMPULAN}

\section{Kesimpulan}

Berdasarkan penelitian yang telah dilakukan maka dapat disimpulkan beberapa hal sebagai berikut :

1. Perbandingan bubuk kulit ari biji kakao : ekstrak kulit buah jeruk nipis berpengaruh sangat nyata terhadap $\mathrm{pH}$, daya sebar, kapasitas antioksidan, tingkat kecerahan (L*), tingkat kemerahan $\left(\mathrm{a}^{*}\right)$, dan tingkat kekuningan (b*) krim. Perlakuan waktu pengadukan berpengaruh nyata terhadap tingkat kecerahan $\left(\mathrm{L}^{*}\right)$ krim. Perlakuan perbandingan bubuk kulit ari biji kakao : ekstrak kulit buah jeruk nipis, waktu pengadukan serta interaksi antara kedua perlakuan berpengaruh sangat nyata terhadap viskositas bodi krim.

2. Perlakuan perbandingan bubuk kulit ari biji kakao : ekstrak kulit buah jeruk nipis $7,14: 7,14$ gram $(1: 1)$ serta waktu pengadukan 15 menit merupakan perlakuan terbaik yang dapat 
menghasilkan produk krim, dengan karakteristik nilai $\mathrm{pH} 6,35$, daya sebar $6,10 \mathrm{~cm}$, viskositas $28.100 \mathrm{cp}$, rasio pemisahan $=1$, kapasitas antioksidan $125,33 \mathrm{mg}$ GAEAC/L, tingkat kecerahan (L*) 43,78, tingkat kemerahan (a*) 6,73 dan tingkat kekuningan $\left(b^{*}\right)$ 10,56.

\section{Saran}

Berdasarkan hasil penelitian ini, untuk menghasilkan produk bodi krim dengan karakteristik terbaik disarankan beberapa hal sebagai berikut :

1. Menggunakan perbandingan bubuk kulit ari biji kakao : ekstrak kulit buah jeruk nipis $7,14: 7,14$ gram $(1: 1)$ dengan waktu pengadukan 15 menit.

2. Perlu dilakukan penelitian lebih lanjut mengenai umur simpan dan total cemaran mikroba pada bodi krim agar bodi krim menjadi lebih aman digunakan untuk kepeluan sehari-hari.

Tabel 9. Hasil uji indeks efektivitas untuk menentukan perlakuan terbaik produk krim bubuk kulit ari biji kakao dan ektrak kulit buah jeruk nipis

\begin{tabular}{|l|l|l|l|l|l|l|l|l|l|}
\hline Variabel & & $\mathrm{pH}$ & $\begin{array}{c}\text { Daya } \\
\text { Sebar }\end{array}$ & Viskositas & $\mathrm{L}^{*}$ & $\mathrm{a}^{*}$ & $\mathrm{~b}^{*}$ & $\begin{array}{c}\text { Kapasitas } \\
\text { Antioksidan }\end{array}$ & Jumlah \\
\hline & $\mathrm{BV})$ & 4,20 & 7,60 & 6,80 & 2,80 & 1,40 & 2,20 & 6,40 & 36,00 \\
\hline & $\mathrm{BN})$ & 0,12 & 0,21 & 0,19 & 0,08 & 0,04 & 0,06 & 0,18 & 1,00 \\
\hline P1X1 & $\mathrm{Ne}$ & 1,00 & 1,00 & 0,00 & 0,98 & 0,00 & 0,99 & 0,00 & \\
\hline & $\mathrm{Nh}$ & 0,12 & 0,21 & 0,00 & 0,08 & 0,00 & 0,06 & 0,00 & $\mathbf{0 , 4 6}$ \\
\hline P1X2 & $\mathrm{Ne}$ & 0,75 & 0,66 & 0,17 & 1,00 & 0,03 & 0,96 & 0,22 & \\
\hline & $\mathrm{Nh}$ & 0,09 & 0,14 & 0,03 & 0,08 & 0,00 & 0,06 & 0,04 & 0,44 \\
\hline P1X3 & $\mathrm{Ne}$ & 0,87 & 0,51 & 0,31 & 0,97 & 0,04 & 1,00 & 0,18 & \\
\hline & $\mathrm{Nh}$ & 0,10 & 0,11 & 0,06 & 0,08 & 0,00 & 0,06 & 0,03 & 0,44 \\
\hline P2X1 & $\mathrm{Ne}$ & 0,12 & 0,21 & 0,41 & 0,73 & 0,43 & 0,65 & 0,55 & \\
\hline & $\mathrm{Nh}$ & 0,01 & 0,04 & 0,08 & 0,06 & 0,02 & 0,04 & 0,10 & 0,35 \\
\hline & $\mathrm{Ne}$ & 0,13 & 0,16 & 0,47 & 0,62 & 0,42 & 0,67 & 0,66 & \\
\hline P2X3 & $\mathrm{Nh}$ & 0,01 & 0,03 & 0,09 & 0,05 & 0,02 & 0,04 & 0,12 & 0,36 \\
\hline & $\mathrm{Ne}$ & 0,13 & 0,07 & 0,60 & 0,67 & 0,54 & 0,68 & 0,81 & \\
\hline P3X1 & $\mathrm{Ne}$ & 0,01 & 0,02 & 0,11 & 0,05 & 0,02 & 0,04 & 0,14 & 0,40 \\
\hline & $\mathrm{Nh}$ & 0,00 & 0,02 & 0,14 & 0,01 & 0,03 & 0,00 & 0,18 & 0,38 \\
\hline P3X2 & $\mathrm{Ne}$ & 0,37 & 0,00 & 0,89 & 0,12 & 1,00 & 0,00 & 0,84 & \\
\hline & $\mathrm{Nh}$ & 0,04 & 0,00 & 0,17 & 0,01 & 0,04 & 0,00 & 0,15 & 0,41 \\
\hline P3X3 & $\mathrm{Ne}$ & 0,00 & 0,00 & 1,00 & 0,00 & 0,81 & 0,03 & 0,91 & \\
\hline & $\mathrm{Nh}$ & 0,00 & 0,00 & 0,19 & 0,00 & 0,03 & 0,00 & 0,16 & 0,38 \\
\hline
\end{tabular}

Keterangan:

$\mathrm{Ne}=$ nilai efektivitas

$\mathrm{BV}=$ bobot variabel

$\mathrm{Nh}=$ nilai hasil $(\mathrm{Ne} \times \mathrm{BN})$

$\mathrm{BN}=$ bobot

P1= perbandingan bubuk kulit ari biji kakao : ekstrak kulit buah jeruk nipis $1: 1$

$\mathrm{P} 2$ = perbandingan bubuk kulit ari biji kakao : ekstrak kulit buah jeruk nipis $2: 1$

P3 = perbandingan bubuk kulit ari biji kakao : ekstrak kulit buah jeruk nipis $3: 1$

$\mathrm{X} 1=$ waktu pengadukan 15 menit

$\mathrm{X} 2$ = waktu pengadukan 30 menit

X3= waktu pengadukan 45 menit 


\section{DAFTAR PUSTAKA}

Adindaputri, Z., N. Purwanti., I. A. Wahyudi. 2013. Pengaruh Ekstrak Kulit Jeruk Nipis (Citrus Aurantifolia Swingle) Konsentrasi 10\% Terhadap Aktivitas Enzim Glukosiltransferase Streptococcus mutans. Maj Ked Gi. 20(2) : 126-13.

Ansel, C. H. 2005. Pengantar Bentuk Sediaan Farmasi. Penerjemah F, Ibrahim. Universitas Indonesia, Jakarta.

[AOAC] Association of Official Analitical Chemist. 2005. Official Methods of Analysis of The Association of Official Analytical Chemist 18th Edition. Gaithersburg, USA.

Arlorio, M., J. D. Coisson., F. Travaglia., F. Varsaldi., G. Miglio., G. Lombardi., and A. Martelli. 2005. Antioxidant and Biological Activity of Phenolic Pigments from Theobroma cacao Hulls Extracted with Supercritical $\mathrm{CO}_{2}$. Article of Food Research International. 38: 1009 - 1014.

Badan Standarisasi Nasional. 1996. Sediaan Tabir Surya SNI 2016-4399-1996. Standar Nasional Indonesia, Jakarta.

De Garmo, E. P., W. G. Sullivan, and C. R. Canada. 1984. Engineering Economy. Macmillan Publisher, New York.

Dewi, R., A. Effionora. 2014. Uji Stabilitas Fisik Formula Krim yang Mengandung Ekstrak Kacang Kedelai (Glycine max). Pharm Sci Res. 1 (3) : 194 - 208.

Elfiyani, R., K. Yati., S. Nurhayati., N. M. A. Lestari. 2013. Perbandingan Penggunaan Setil Alkohol dan Setostearil Alkohol Sebagai Thickening Agent terhadap Stabilitas Fisik Scalp Lotion Ekstrak Etanol $99 \%$ Buah Mengkudu (Morinda citrifolia. L). Jurnal Farmasains. 2 (1) : 31 - 37.
Iswindari, D. 2014. Formulasi dan Uji Antioksidan Krim Rice Bran Oil. Skripsi. Tidak dipublikasikan. UIN Syarif Hidayatullah, Jakarta.

Kusumowardani, R. R. 2010. Optimasi Komposisi Emulsivying Agent Tween 80 dan Span 80 dalam Virgin Coconut Oil Cream : Aplikasi Desain Faktorial. Skripsi.Tidak dipublikasikan. Fakultas Farmasi Universitas Sanata Dharma, Yograkarta.

Lecumberri, E., R. Mateos., M. I. Pulido., P. Ruperez., L. Goya., and L. Bravo. (2007). Dietary fibre composition, antioxidant capacity and physicochemical properties of a fibre-rich product from cocoa (Theobroma cacao L.). Food Chemistry 104: 948-954.

Minifie, B. W. 1984, Chocolate, Cocoa and Confectionary. Science and Technology, $2^{\text {nd }}$ edition.VA Churcil 104,London

Nindyasari, S. 2012. Pengaruh Suhu dan Waktu Penyeduhan Teh Hijau (Camllia sinensis) serta Proses Pencernaan In Vitro Terhadap Aktivitas Inhibisi Lipase. Skripsi. Tidak Dipublikasikan. Fakultas Teknologi Pertanian IPB, Bogor.

Rachmalia, N., I. Mukhlishah., N. Sugihartini., T. Yuwono. 2016. Daya Iritasi dan Sifat Fisik Sediaan Salep Minyak Atsiri Bunga Cengkeh (Syzigium aromaticum) pada Basis Hidrokarbon. Majalah Farmaseutik. 12 (1) : $372-376$.

Rizqi, A., S, Kumalaningsih., A. F. Mulyadi. 2014. Studi Pemanfaatan Bentonit untuk Penjernihan Minyak Atsiri Daun Cengkeh (Kajian Waktu Reaksi dan Konsentrasi Bentonit). Thesis for Bachelor Degre. Fakultas Teknologi Pertanian Unibraw, Malang. 
Sandrasari, D. A. 2008. Kapasitas Antioksidan dan Hubungannya dengan Nilai Total Fenol Ekstrak Sayuran Indigenous. Skripsi S2. Tidak dipublikasikan. Sekolah Pascasarjana ITB, Bogor.

Sartini., M. N. Djide., G. Alam. 2007. Ekstraksi Komponen Bioaktifdari Limbah Kulit Buah Kakaodan Pengaruhnya terhadap Aktivitas Antioksidan dan Antimikroba. Universitas Hasannudin, Makasar.

Schmitt, W. H. 1996. Skin Care Products. Cosmetics and Toiletries Industry $2^{\text {nd }}$ Edition. Blackie Academic and Profesional, London.

Simangunsong, F. M. P., S. Mulyani., A. Hartiati. 2018. Evaluasi Karakteristik Krim Ekstrak Kunyit (Curcuma domestica Val.) Pada Berbagai Formulasi. Jurnal Rekayasa dan Manajemen Agroindustri. 6 (1) : 11-21.

Smaoui, S., Hilma, H. B., Jarraya, R, Kamoun, N. G., Ellouze, R, Damak, M.
2012. Cosmetic Emulsion of Virgin Coconut Oil : Formulation and Biophysical Evaluation African Journal of Biotechnology. 11 (40) : $9664-$ 9671.

Umaroh, A. 2015. Pengaruh Perbandingan Ekstrak Kulit Buah Kakao dan Kulit Buah Jeruk Nipis Terhadap Sifat Organoleptik Lulur Bekatul. E-jurnal. 4 (2) : $1-8$.

Voight, R. 1994. Buku Pelajaran Teknologi Farmasi Gadjah Mada University Press, Yogyakarta.

Weaver, C. 1996. The Food Chemistry Laboiratory. CRC Press, Boca Raton, New York, London, Tokyo.

Yunilawati, R. Y., Y. Komalasari. 2011. Penggunaan Emulsifier Stearil Alkohol Etoksilat Derivat Minyak Kelapa Sawit Pada Produk Losion dan Krim. Jurnal Kementrian Perindustrian. 33(1) : 8389. 